\title{
Echinococcus granulosus: specific quantification of the two most immunoreactive antigens in hydatid fluids
}

\author{
P. MUSiani, M. Piantelli, L. LAURiola, E. ARRU, AND R. POZzUOLI \\ From the Department of Pathology, Università Cattolica S. Cuore, Rome, and the Department of \\ Parasitic Disease, University of Sassari, Sassari, Italy
}

SUMMARY Preparations of the two most immunoreactive Echinococcus granulosus antigens (antigens 4 and 5) from sheep hydatid fluid, purified by a simplified method, and monospecific antisera against antigens 4 and 5 , prepared by a new procedure, were used to measure the antigenic concentrations of antigens 4 and 5 in swine, sheep, and human hydatid fluids from pulmonary or hepatic cysts. Two bovine samples and two commercial preparations were also tested. The concentration of both antigens was significantly higher in sheep and human hydatid fluids than in swine hydatid fluid. The antigenic content of the two bovine samples and of the two commercial preparations was below the sensitivity level of the method employed. Independently of the species tested, the amount of Echinococcus antigens was greater in hepatic than in pulmonary cysts. The ratio between the concentrations of antigens 4 and 5 was constant at about 1:10 in the samples from various organs and from different species. When there were enough samples for statistical analysis a linear correlation was found between the contents of these two antigenic components but there was none between the amounts of proteins and the antigenic concentrations in the single cysts. Sheep hydatid fluid must therefore be considered the best source of antigenic material for diagnostic purposes even though in human cysts the antigenic fraction is less contaminated by serum proteins. We describe a reliable method of standardising antigenic material for the immunodiagnosis of hydatid disease.

Serological tests for hydatidosis in man are hampered by the lack of specific standardised parasitic antigenic material. Recently Echinococcus granulosus antigens have been isolated (Pozzuoli et al., 1972) and two of them (antigens 4 and 5) have the highest immunoreactivity (Pozzuoli et al., 1974, 1975). These purified antigens, apart from their direct use in serological tests, can be used to standardise the most often used and commercially available antigenic materialnamely, hydatid fluid obtained from different sources.

This paper reports the concentrations of antigens 4 and 5 in hydatid cyst fluids from various organs and various animal species. These concentrations were measured by a radial immunodiffusion technique using monospecific anti-antigen 4 and antiantigen 5 antisera obtained by a simple procedure. Our goal was to identify the best material for immunodiagnostic tests in order to standardise the methods and the materials used in various laboratories.

Received for publication 20 October 1977

\section{Material and methods}

ECHINOCOCCUS ANTIGENS

Echinococcus antigens 4 and 5 (EA) were purified from sheep hydatid fluid (SHF). Crude SHF was collected, concentrated, and cleared as previously reported (Pozzuoli et al., 1972) without lyophilisation. The fluid concentrated to $3-4 \mathrm{~g}$ protein $/ 100 \mathrm{ml}$ was dialysed against $0.05 \mathrm{M}$ acetate buffer, $\mathrm{pH} 5.0$, according to the procedure of Oriol et al. (1971). The precipitated proteins containing antigens 4 and 5 were then solubilised in $0.1 \mathrm{M}$ phosphate buffer (pH 7.6), $0.5 \mathrm{M} \mathrm{NaCl}$, and applied to an immunoadsorbent column containing rabbit anti-sheep serum antibodies covalently coupled to Sepharose 4B (Cuatrecasas et al., 1968). The material thus obtained when injected into rabbits elicits antibody formation only against Echinococcus antigens 4 and 5 (aEA) (see Figure).

Antigen 5 was prepared from the purified material containing both antigens 4 and 5 . Proteins were dialysed overnight at $4^{\circ} \mathrm{C}$ against a $0.2 \mathrm{M}$ glycine- 


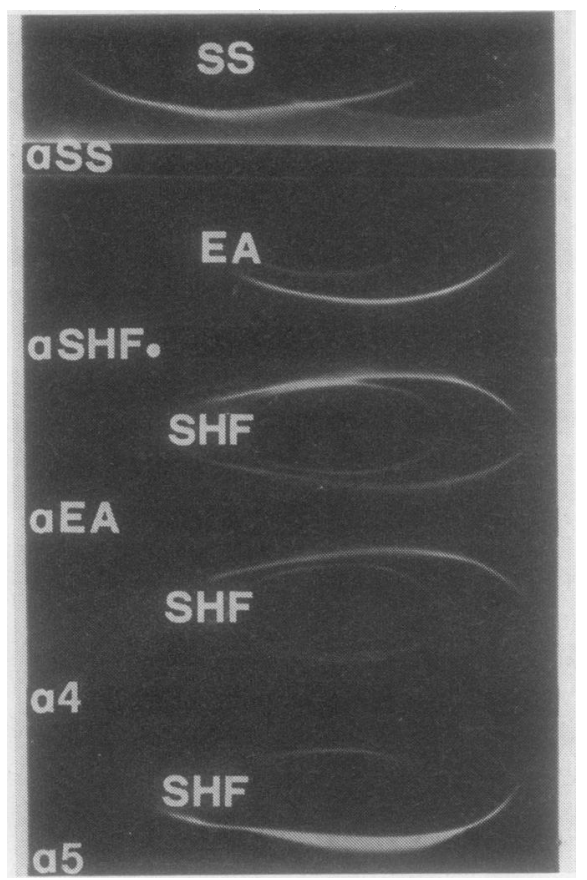

Immunoelectrophoretic patterns of sheep serum (SS), purified preparation of Echinococcus granulosus antigens 4 and $5(E A)$, and sheep hydatid fluid (SHF) tested against rabbit antisera anti-sheep serum (aSS), adsorbed anti-sheep hydatid fluid (aSHF.), antiEchinococcus antigens 4 and 5 (aEA), anti-antigen 4 (a4), and anti-antigen 5 (a5). The immunoelectrophoretic pattern of the purified preparation of Echinococcus antigens 4 and $5(E A)$ tested against aSHF. shows only two precipitation lines, identifiable as antigens 4 and 5 . No precipitation lines are present when the same material is tested against aSS. The serum against antigen 4 (a4) and the serum against antigen $5(a 5)$ when tested against $\mathrm{SHF}$ give a single precipitation line, which is that determined by antigen 4 and by antigen 5 respectively.

$\mathrm{HCl}$ buffer ( $\mathrm{pH} \mathrm{2.8)}$ and then heated for five minutes at $100^{\circ} \mathrm{C}$. The precipitate thus formed was removed by centrifugation at $20000 \mathrm{rpm}$ for $\mathbf{3 0}$ minutes. The recovered supernatant was neutralised by adding $1 \mathrm{~N} \mathrm{NaOH}$. Sera from rabbits immunised with this final preparation contained antibodies only against antigen 5 (a5).

Echinococcus antigens 4 and 5 were also separately obtained from sheep hydatid fluid as previously reported (Pozzuoli et al., 1975).

ANTISERA

Anti-sheep serum (aSS) and adsorbed anti-SHF
(aSHF) were prepared as previously reported $\frac{\stackrel{0}{*}}{2}$ (Pozzuoli et al., 1972).

Anti-Echinococcus antigens 4 and 5 rabbit serum $\overrightarrow{\vec{F}}$ (aEA) and anti-antigen 5 rabbit serum (a5) were $\stackrel{?}{+}$ obtained by injecting $1 \mathrm{mg}$ protein plus $0.5 \mathrm{ml}$ ? Freund's complete adjuvant into foot pads of adult $\frac{\bar{C}}{\bar{C}}$ New Zealand animals followed by booster in- $\frac{\pi}{\sigma}$ jections after 20 and 30 days.

A monospecific antiserum against antigen 4 (a4) ڤ was prepared by adsorption of the anti-antigen $5 \overrightarrow{0}$ antibodies present in the anti-antigen 4 and 5 serum (aEA). $200 \mathrm{mg}$ protein of the purified antigen $5 \vec{\omega}$ preparation was dialysed against $0.01 \mathrm{M}$ phosphate, pH 7.4, $0.5 \mathrm{M} \mathrm{NaCl}$, and then coupled to $4 \mathrm{~g}$ silica? supports (Biomaterial GAO-3940 supports, Corning $\omega_{\vec{C}}$ Biological Products, Medfield, Mass, USA) using a icr $2.5 \%$ aqueous glutaraldehyde solution. Immuno- adsorption was done by a batch procedure for three $\mathrm{G}$ hours at room temperature. On each occasion $20 \mathrm{ml}$ 은 anti-EA antiserum was incubated with the immo- $\overrightarrow{-}$ bilised antigen 5 preparation. Regeneration of the immunoadsorbent was performed with $1 \mathrm{M} \mathrm{K}$ thiocyanate solution in $0.01 \mathrm{M}$ phosphate buffer $\overrightarrow{0}$ (pH 7.4), $0.5 \mathrm{M} \mathrm{NaCl}$.

Polyacrylamide gel disc electrophoresis was carried out on $5 \%$ gels following the procedure described by Laemmli (1970). Microdensitometry, using a Kipp and Zonen (Delft, Holland) integrating microdensitometer, was performed on the gel, $\stackrel{\odot}{\triangle}$ which contained $100 \mu \mathrm{g}$ protein of Echinococcus $\overrightarrow{\vec{F}}$ purified antigens 4 and 5 stained with Coomassie $\frac{O}{3}$ Brilliant Blue.

Radial-immunodiffusion was performed by the procedure described by Mancini et al. (1965) using monospecific rabbit antisera against antigen 4 ando against antigen 5. As standards, purified antigen 4 , $\frac{0}{3}$ purified antigen 5 (Pozzuoli et al., 1975), and. appropriate dilutions of EA preparation (containing ${ }_{\mathcal{\beta}}$ both antigens) were used.

Hydatid fluid (HF) samples aspirated by syringe을 directly from parasitic fertile cysts were filtered and $>$ stored at $-25^{\circ} \mathrm{C}$ until used: 83 samples were collected-15 from swine cysts (six from liver and nine from lung), 58 from sheep cysts (26 from liver and 32 from lung), two from bovine cysts 0 (one from liver and one from lung), and six from $\omega$ human cysts (three from liver and three from lung) All these samples except human HF were collectedo in many abattoirs of Northern Sardinia (Italy). One $\bar{\varnothing}$ commercial sample of swine or bovine hydatid $\stackrel{?}{+}$ fluid from Behringwerke AG (Marburg-Lahn, West Germany, preparation $65 \mathrm{~B})$ and one of sheep? hydatid fluid from Istituto Sieroterapico Milanese (Milan, Italy, preparation 61) were purchased.

Protein determination was performed by Folin'so method (Lowry et al., 1951) using as a reference 
purified sheep albumin (Fraction V, Pentex, Miles Laboratories, Kankakee, Ill, USA).

\section{Results}

\section{RELATIVE CONCENTRATION OF ANTIGEN 4} AND 5 IN EA PREPARATION

Disc electrophoresis of EA on $5 \%$ polyacrylamide gel showed two bands. Microdensitometric evaluation indicated that the more anodic band, corresponding to antigen 5 (Piantelli et al., 1977), accounted for about $89-91 \%$ and the more cathodic, identifiable as antigen 4 (Piantelli et al., 1977), for most of the remaining applied proteins $(8-10 \%)$.

CONCENTRATION OF ANTIGEN 4 AND ANTIGEN 5 IN HF SAMPLES

Concentrations of the two antigens were determined by radialimmunodiffusion in agarose gels containing anti-antigen 4 or anti-antigen 5 antisera. As standard we used suitable amounts of antigen 4 and antigen 5 and appropriate dilutions of EA preparation containing $5 \mathrm{mg} / \mathrm{ml}$ of protein. Therefore concentrations of $4.5 \mathrm{mg} / \mathrm{ml}$ for antigen 5 and $0.5 \mathrm{mg} / \mathrm{ml}$ for antigen 4 were calculated from densitometric analysis. The relative concentrations of proteins, antigen 4 , and antigen 5 in HF samples from swine, sheep, and human are shown in the Table. Neither antigen 5 nor antigen 4 were determinable by immunodiffusion technique in the two bovine samples and the two diagnostic HF from commercial sources, while the protein concentrations were 0.39 and $1.2 \mathrm{mg} / \mathrm{ml}$ for bovine fluids and 0.58 and $0.56 \mathrm{mg} / \mathrm{ml}$ for commercial preparations.

Similar results were obtained using isolated 4 or 5 antigen as standard instead of EA preparation. As shown in the Table, the lowest protein concentration was found in human HF while the highest was observed in sheep HF, particularly in liver SHF (protein concentration: liver SHF versus lung SHF $\mathbf{P}<0.01$ ).

The concentrations of antigen 4 and 5 were higher in sheep and human HF than in swine. The highest content of both antigen 4 and 5 was found in sheep hepatic cysts. Furthermore, the concentrations of antigens 4 and 5 were significantly higher (respectively $P<0.01$ and $P<0.001$ ) in hepatic SHF than in pulmonary SHF. Expressed as a proportion of the total protein concentration the highest content was in human lung HF, the lowest in swine fluids. The data in the Table also indicate that the ratio between antigen 4 and antigen 5 concentration was roughly $1: 10$ to $1: 11$. Moreover, a linear correlation was found between antigen 4 and antigen 5 concentrations in both pulmonary and hepatic SHF ( $r=0.98 ; P<0.01)$.

\section{Discussion}

Hydatid fluid contains at least 10 parasitic antigens. Two of them, antigen 4 and 5, are of most diagnostic interest. We have found antigen 4 in particular to be most immunoreactive and specific (Capron et al., 1968, 1970; Pozzuoli et al., 1975) while antigen 5 has been regarded as a lipoprotein common to several parasites (Bout et al., 1974). However, whereas antigen 5 could be easily purified antigen 4 could be prepared only in small amounts and by rather complex procedures (Pozzuoli et al., 1975).

We have described in this paper an easy method of preparing monospecific anti-antigen 4 and antiantigen 5 antisera by two key steps: firstly, denaturation of antigen 4 in EA preparation and, secondly, adsorption of anti-antigen 5 antibodies, contained in anti-EA antiserum, using immobilised antigen 5 still present after EA denaturation. This method does not require isolation of antigen 4 . We used the monospecific antisera prepared in this way to quantify antigens 4 and 5 in hydatid fluids by the radialimmunodiffusion technique.

Our quantitative results show that sheep and human HF contain significantly higher concentrations of both Echinococcus antigens 4 and 5 than swine HF. The antigenic content of the two bovine HF samples was very low since it was not determinable by our procedure. The different EA concentrations in the cysts of the animal species tested may reflect, at least in Italy, a variable degree of

Table Concentrations of protein and antigens 4 and 5 in hydatid fluids

\begin{tabular}{|c|c|c|c|c|c|}
\hline Source & $\begin{array}{l}\text { No. of } \\
\text { samples }\end{array}$ & $\begin{array}{l}\text { Antigen } 4 \\
(m g / m l \pm S D)\end{array}$ & $\begin{array}{l}\text { Antigen } 5 \\
(m g / m l \pm S D)\end{array}$ & $\begin{array}{l}\text { Protein } \\
(m g / m l \pm S D)\end{array}$ & $\begin{array}{l}\text { Antigen } 4+5 \\
\% \text { total protein }\end{array}$ \\
\hline Swine lung & 9 & ND & $0.021 \pm 0.004$ & $1 \cdot 017 \pm 0.170$ & $2 \cdot 1$ \\
\hline , liver & 6 & ND & $0.024 \pm 0.011$ & $1.006 \pm 0.285$ & $2 \cdot 4$ \\
\hline Sheep lung & 32 & $0.0064 \pm 0.0034$ & $0.054 \pm 0.011$ & $1.432 \pm 0.306$ & $4 \cdot 2$ \\
\hline , liver & 26 & $0.0089 \pm 0.0037$ & $0.088 \pm 0.031$ & $1.667 \pm 0.252$ & $5 \cdot 8$ \\
\hline Human lung & 3 & $0.0051 \pm 0.0029$ & $0.053 \pm 0.013$ & $0.615 \pm 0.098$ & $9 \cdot 4$ \\
\hline ", liver & 3 & $0.0069 \pm 0.0033$ & $0.059 \pm 0.018$ & $0.884 \pm 0.113$ & $7 \cdot 4$ \\
\hline
\end{tabular}

ND $=$ not determinable. 
host-parasite adaptation. Moreover, independently of the species tested, there were more EA in hepatic than in pulmonary cysts. Thus sheep liver seems to provide the best environment for cystic growth.

The ratio between the concentrations of antigens 4 and 5 is constant (about 1:10) in the HF samples from various organs of different species. But despite the greater amount of antigen 5 in HF-particularly when the molecular weights of antigen $5(150000)$ and antigen 4( $>400000$ ) (Oriol et al., 1971; Pozzuoli et al., 1972) are considered-it is important to note that only antibodies against antigen 4 are regularly found in patients with hydatid infection while anti-antigen 5 antibodies are less often detected (Pozzuoli et al., 1975).

No linear correlation was found between the amount of proteins and the antigenic concentrations in the single cysts. Hydatid fluid contains a mixture of host serum proteins with a minor fraction of parasitic proteins almost completely represented by antigens 4 and 5 . In human cysts the antigenic material is less contaminated by serum proteins than in other species. However, obviously human HF cannot be considered a suitable source of antigenic material for diagnostic purposes. Therefore, according to our findings, sheep HF should be the best source of antigenic material for serological diagnostic tests. No antigenic material was detectable in the two commercial preparations we tested.

We conclude that to obtain a reliable standardisation of the reagents for the immunodiagnosis of hydatid disease the amount of antigen 4 and antigen 5 in HF preparations must be determined.

We gratefully acknowledge the expert technical assistance of $\mathrm{Mr}$ Paolo Baldassarri.

\section{References}

Bout, D., Fruit, J., and Capron, A. (1974). Purification d'un antigène spécifique de liquide hydatique. Annales
d'Immunologie, 125C, 775-778.

Capron, A., Biguet, J., Vernes, A., and Afchain, D. (1968). Structure antigénique des helminthes. Aspect immunologiques des relations hôte-parasite. Patho logie et Biologie, 16, 121-138.

Capron, A., Yarzabal, L., Vernes, A., and Fruit, 혼 (1970). Le diagnostic immunologique de l'échinococs cose humaine (bilan personnel à propos de $40 \Phi_{0}$ observations). Pathologie et Biologie, 18, 357-365.

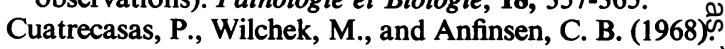
Selective enzyme purification by affinity chromato $\overrightarrow{0}$ graphy. Proceedings of the National Academy of Sciences, 61, 636-643.

Laemmli, U. K. (1970). Cleavage of structural proteins? during the assembly of the head of bacteriophage T48 Nature, 227, 680-685.

Lowry, O. H., Rosebrough, N. J., Farr, A. L., and్ Randall, R. J. (1951). Protein measurement with the folin phenol reagent. Journal of Biological Chemistry 193, 265-275.

Mancini, G., Carbonara, A. O., and Heremans, J. F?을 (1965). Immunochemical quantitation of antigens by single radial immunodiffusion. Immunochemistry, 20 235-254.

Oriol, R., Williams, J. F., Pérez Esandi, M. V. and Oriolş C. (1971). Purification of lipoprotein antigens of̂ Echinococcus granulosus from sheep h ydatid fluid American Journal of Tropical Medicine and Hygiene, 20 ? 569-574.

Piantelli, M., Pozzuoli, R., Arru, E., and Musiani, P⿳亠丷厂 (1977). Echinococcus granulosus: identification oहै major antigen subunits. Journal of Immunology 119, 1382-1386.

Pozzuoli, R., Musiani, P., Arru, E., Patrono, C., anch Piantelli, M. (1974). Echinococcus granulosus: evalua tion of purified antigens immunoreactivity. Experi mental Parasitology, 35, 52-60.

Pozzuoli, R., Musiani, P., Arru, E., Piantelli, M., anक़्̣ Mazzarella, R. (1972). Echinococcus granulosus:isolation and characterization of sheep hydatid fluid antigens. Experimental Parasitology, 32, 45-55.

Pozzuoli, R., Piantelli, M., Perucci, C., Arru, E., ang Musiani, P. (1975). Isolation of the most immunoreactive antigens of Echinococcus granulosus from sheeps hydatid fluid. Journal of Immunology, 115, 1459-1463. I 